\title{
Endurance and Damage in Fatigue of Symmetrical Configuration 2P-2V-2P Perlon-Glass-Acrylic Composite Laminates of Orthopaedic Use
}

\author{
Bachir Redjel $^{1, *}$, Sihem Achouri ${ }^{2}$ \\ ${ }^{1}$ Civil Engineering Laboratory (LGC), Badji Mokhtar University, Algeria \\ ${ }^{2}$ Research Center in Industrial Technologies CRTI, P. O. Box 64 Cheraga 16014 Algiers, Algeria
}

Copyright $\bigcirc 2019$ by authors, all rights reserved. Authors agree that this article remains permanently open access under the terms of the Creative Commons Attribution License 4.0 International License

\begin{abstract}
In this paper, an experimental characterization of fatigue behaviour on prismatic specimens of a symmetrical laminated composite material perlon- glass- acrylique $2 \mathrm{P}-2 \mathrm{~V}-2 \mathrm{P}$ for orthopaedic use is conducted. Cyclic repeated solicitation is employed corresponding to applied minimum stress $\sigma_{\min }$ equal zero. The various loading levels imposed on the specimens are $80 \%, 70 \%, 60 \%, 55 \%, 45 \%, 35 \%$ and $25 \%$ of the value of the static failure strength measured in flexure. A significant scatter characterizes the results of material fatigue lifetime. That is the consequence of the heterogeneity of the material structure. The scattered phenomenon prevents any prediction of the lifetime with a good probability using Wohler equation. This enables defining a constant degradation rate by $10 \%$ cycle decade. The microstructure morphology study through microscopic observations is also discussed and analyzed. The damage state in fatigue is characterized by a combination of density and orientation of micro-cracks. This damage is mainly due to mechanisms complexity of matrix micro-cracking, inter facial exfoliation, debonding and delamination. The damage evolution stages in the case of cyclic loading have the same nature than those found in static loading but have different chronology and scale.
\end{abstract}

Keywords Perlon, Acrylic, Orthopaedic, Fatigue, Scatter

\section{Introduction}

The laminated composite materials are being able to have high mechanical performances. They have been extensively used in all fields of industry and are the origin of great challenges in various high technology achievements (Perrot 2006). Their mechanical behavior has been widely analyzed during the last decades because of design issues involved in the manufacture and use of these particular composite structures.

The composites containing glass fiber reinforced the acrylic resin are the composites most used in the industry of orthopaedic equipment manufacture used for handicapped people. According to the formulation and requirements' of use, they can be appeared as products light, transparent, translucent or opaque, colored or colorless without limitation as for the object sizes. However the analysis of the mechanical behavior of these laminated composite materials under the influence of different requirements remains very complex and predicting their properties remains poorly controlled. This difficulty is mainly related to three-phase constitution of these materials (resin, fiber reinforcement, various additions) and to the complexity of the deformation mechanisms at the microscopic level (heterogeneity, anisotropy...) (Redjel and De Charentenay 1987, Belaadi et al. 2014, Boukharouba et al. 2014).

All the materials using the manufacture of the apparatuses of prosthesis or orthopaedic must be of first choice and do not have any defect and not to undergo any treatment likely to dissimulate their defects. That it is in static loading or dynamic loading, the stacking sequence of the layers of reinforcement affects the behavior of the laminates and generates various damaging modes involving the fracture (Bezazi 2003). In some cases, it is however possible to identify a majority or critical damage mechanism (Pauchard 2001).

The behavior under mechanical fatigue and failure is still not completely understood (Boukharouba et al 2014). In fatigue the characterization and the prediction of the mechanical behavior of glass fiber reinforced composite materials have been the subject of various studies in order to follow the evolution of mechanical properties during cyclic history and to develop analytical and experimental 
methods improved and the establishment of reliable models. Several studies show that in the case of fatigue of fiber reinforced composite materials, for a given stress level $\sigma_{i}$, a dispersion value of the number of cycles to failure is observed.

The problem of results dispersal is the consequence of the structural heterogeneity and the occurence of defects since (Gonzalo and Dominguez Almaraz 2008). Soh Fotsing et al. (2004) have reported that these defects present in the material are difficult to measure. Thus, it is advisable to use as a random variable, for a given stress level, the number of cycles to failure explain the existence of defects by a probabilistic approach. Ngarmaïm et al. (2014) have formulate a probabilistic model of a new expression of the $S N$ curve in fatigue based on the concept of "weakest link" of Weibull introducing a new parameter $N_{c}$, the number characteristic of cycles corresponding to the failure probability equal to 1 . His confrontation with the terms of the curve most used $S_{N}$, particular those Basquin, the Wöhler and the Stromeyer, the fatigue tests and martensite steels $P 22 O 100 \mathrm{C} 6$ data provided errors of about $5 \%$ maximum for Basquin, Wöhler and the proposed models.

The goal of this specific work is to obtain an improved understanding on the mechanical characterization under fatigue loading of an orthopaedic use perlon-glass reinforced acrylic matrix composite material. This laminate was manufactured by national office of accessories and equipment's for handicapped persons "ONAAPH" of Annaba (Algeria).

\section{Experimental Methodology}

The method of production adopted for the manufacturing specimens is the same as the one used in the manufacture of the prostheses as shown in Fig. 1. The manufacturing process adapted for this type of structures and components is the vacuum molding technique. The elimination of the vacuum within the mould between the two bags is done through an air aspirator. Resin mixture is prepared separately, then poured in the mold quickly.

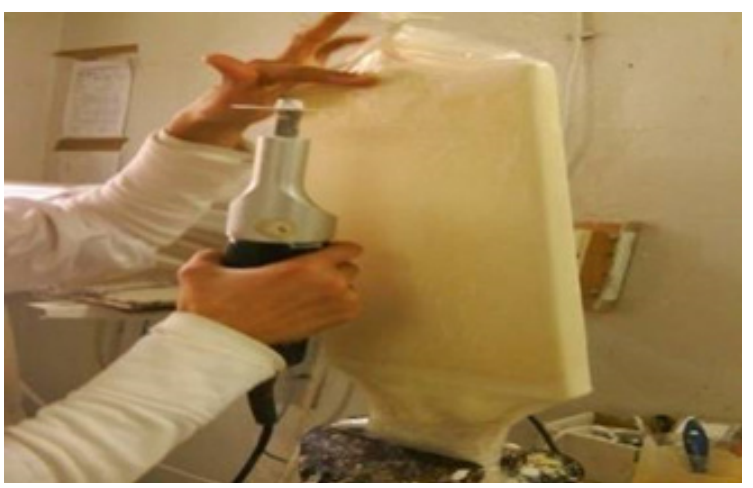

Figure. 1. Manufacture of the composite
The material used for specimens design is a laminate $\mathrm{E}$ glass and perlon layers reinforcements, an acrylic resin initially in the form of viscous liquid and other associated additives that are an acceleration operator, a colouring paste and a hardener. The period of hardened resin varies from 15 to $20 \mathrm{~min}$. The stratification is limited to six layers for samples with reasonable thickness of approximately $4 \mathrm{~mm}$. This laminate is used in the manufacture of orthopaedic prostheses by national office of equipment and accessory for handicapped persons, Annaba - Algeria (ONAAPH).

In this study the concepts of the considered prostheses are those related to the lower limbs as shown in Fig. 2, because they must ensure static body and allow locomotion mutilated. The perlon is stacked on the surface for esthetics and atmospheric strength (moisture). The reinforcements must be drawn and tightened in the direction of stacking. The unit is then covered by a plastic bag. The reinforcements are piled up according to the selected order. The symmetrical configuration considered in the molding direction is: two perlon layers - two layers of glass - two perlon layers designated $2 P-2 V-2 P$.

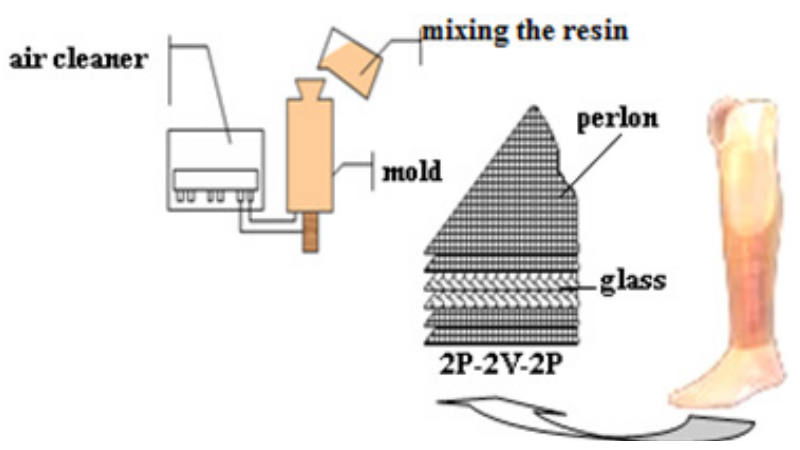

Figure 2. Schematization of the elaborate type of architecture

The acrylic resin is initially supplied in the form of liquid in cans of $4.9 \mathrm{~kg}$ reference with a density at $20^{\circ} \mathrm{C}$ of $1 \mathrm{~g} / \mathrm{cm}^{3}$. The used hardener is a white powder with peroxide of benzoyle and it is used with $3 \%$ in weight of the resin. The time of demolding is about 30 minutes. The used fiberglass is a white silky aspect of $E$ type, with a density of $2.6 \mathrm{~g} / \mathrm{cm} 3$ and a filament of $10 \mu \mathrm{m}$ diameter. The manufactured glass is delivered in the form of roller of $1 \mathrm{~kg}$ in weight, $9.3 \mathrm{~m}$ of length and $20 \mathrm{~cm}$ of diameter.

The perlon used on this study is composed from fibers of PA66 polyamide with fine weaving giving a better flexibility and a good outside aspect. It is in the form of tubular sweater delivered in $1 \mathrm{~kg}$ roller in weight, of $27 \mathrm{~m}$ of length and $15 \mathrm{~cm}$ in diameter, and a density of $1.11 \mathrm{~g} / \mathrm{cm} 3$. This reinforcement is therefore a two-dimensional woven structure intended for the composite material prostheses in order to enhance mechanical and thermal properties. Fig. 3 shows the fabrics architecture of perlon and enlarged glass used as reinforcements. The enlargements were realized on an optical leading microscope Motic with digital consignment endowed with a system with various 
enlargements.

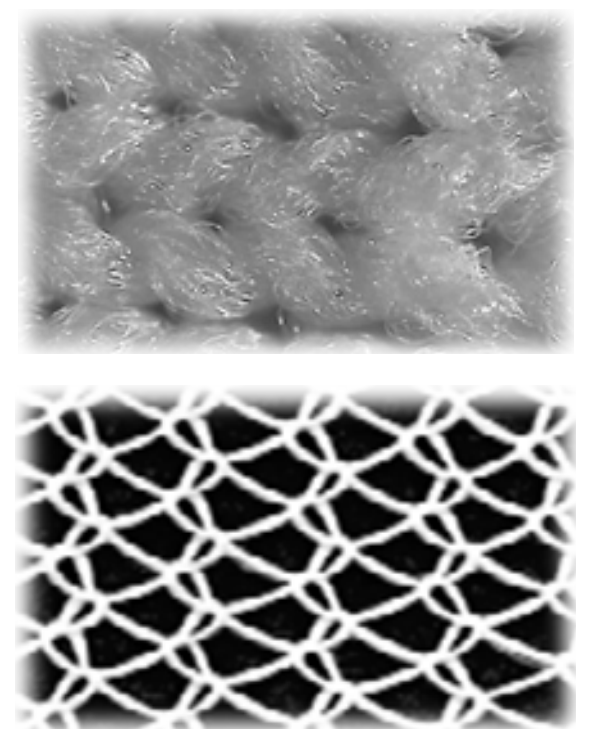

Figure 3. Respectively fabric of perlon $\left(\times 10^{2}\right)$ and E Glass (enlargement $\mathrm{x} 8$ )

The specimens were cut from molded plates using a special articulated head saw with a diamond disk, and were prismatic form of $80 \mathrm{~mm}$ length, $15 \mathrm{~mm}$ width and $4 \mathrm{~mm}$ thickness according to EN ISO 14125 standard (Krawczak). The distance between the two pivots was $64 \mathrm{~mm}$. Fatigue tests were performed in three points bending under load control at different amplitudes with a sinusoidal wave form signal at frequency of $1.25 \mathrm{~Hz}$. Cyclic repeated solicitation was used corresponding to $r_{d}=\sigma_{\min } / \sigma_{\max }=0$. The various loading levels imposed on the specimens are $80,70,60,55$, 45,35 and $25 \%$ of the value of the static failure strength measured in three point bending that is equal to $54 M P a$. For each value of loading level a minimum of three specimens have been tested. A Zwick/Roell Z 020 universal test machine equipped with a load cell of $20 \mathrm{KN}$ and control software test expert II allowing the acquisition and the treatment of data via computer (Fig. 4). To examine the microstructure of the composite, the fracture surfaces of the specimens were analyzed using a Motic type microscope with digital consignment endowed with a system with various enlargements. All fatigue cyclic tests have been carried out at a room temperature of around $25^{\circ} \mathrm{C}$ and an average relative humidity of $60 \%$ to $70 \%$ under load control until samples complete fracture. The bending strength $\sigma$ was calculated by the following classic formula of the strength of materials:

$$
\sigma=\frac{3}{2}\left(\frac{P L}{B W^{2}}\right)
$$

With: $P, L, W$ and $B$ are respectively, the applied load, the distance between supports $(64 \mathrm{~mm})$, the specimen width $(15 \mathrm{~mm})$ and the specimen thickness $(4 \mathrm{~mm})$.

The failure number of cycles is recorded by a device fixed on the test machine.

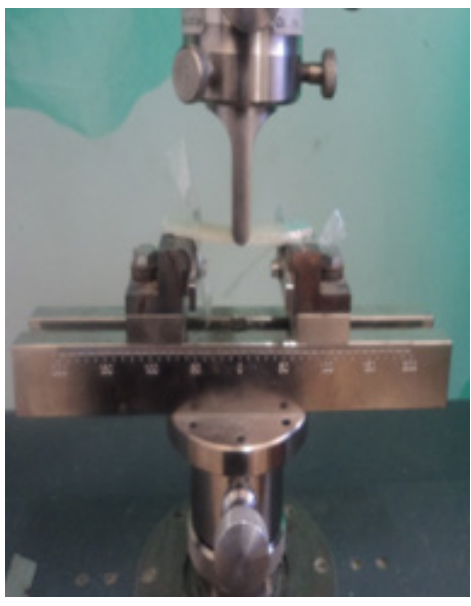

Figure 4. Three point bending device

\section{Results and Discussions}

Example of typical load-deflection curve evolution in bending test is shown on Fig. 5

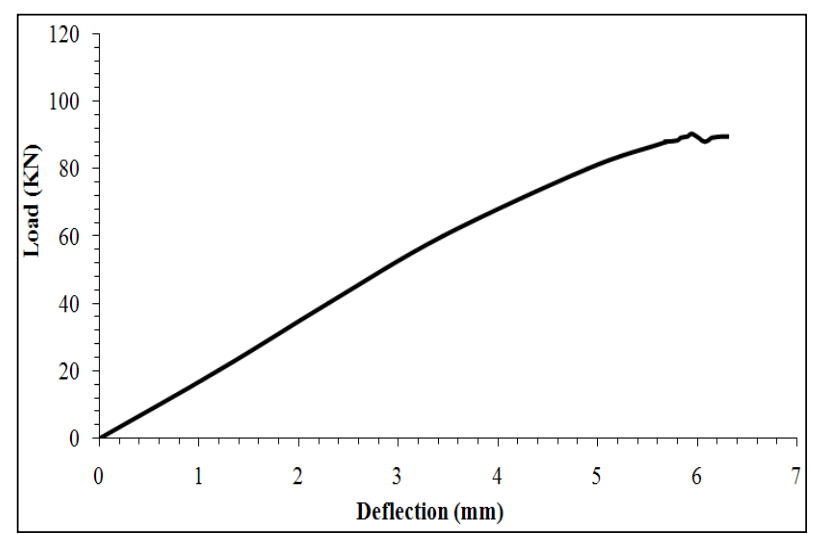

Figure 5. Typical load-deflection curve of laminate composite in three point bending

This curve start by presenting a large linear part which represents the elastic response of the laminate followed by short nonlinear second one where deflection is significant for weak loads and where staircase behavior has registered. This behavior is much more nuanced in bending.

This specific behavior reflects the initiation and the accumulation of the diffuse and progressive damage that occurs within the structure before the total ruin. This is mainly caused by a multi matrix cracking, a mechanism of losing and separation of fibers, fiber-matrix debonding, delamination mechanism that limit or prevent the transfer of the load. Increasing the load causes the development of the micro cracks to the sudden rupture of the specimen at large displacement (Achouri et al 2013, Achouri and Redjel 2014). The fracture is reached at the maximum load value. Latter and in a rather abrupt way the load suddenly falls indicating the saturation of the multi cracking phenomenon. The damaged part is relating both to the 
matrix failure and to the reinforcements. Crack propagation is in the form of a tear of the composite. Practically during the test, the mechanism operates with a frequent change of the direction of the tear. The orientation of this tear probably follows the way of the path of nodes as well as fabric fiber-matrix interface. The damage mechanism dominating remains transverse cracking. In this study, the minimal stress $\sigma_{\min }$ of repeated solicitation has been maintained constant and equal to zero for all the tests. Only the maximal stress $\sigma_{\max }$ and consequently the amplitude of loading were varied. All the results of the experimental tests are reported on Fig. 6 which shows the distribution of the experimental points of the strength amplitude according to the failure number of cycles tradionally called curve of Wöhler.

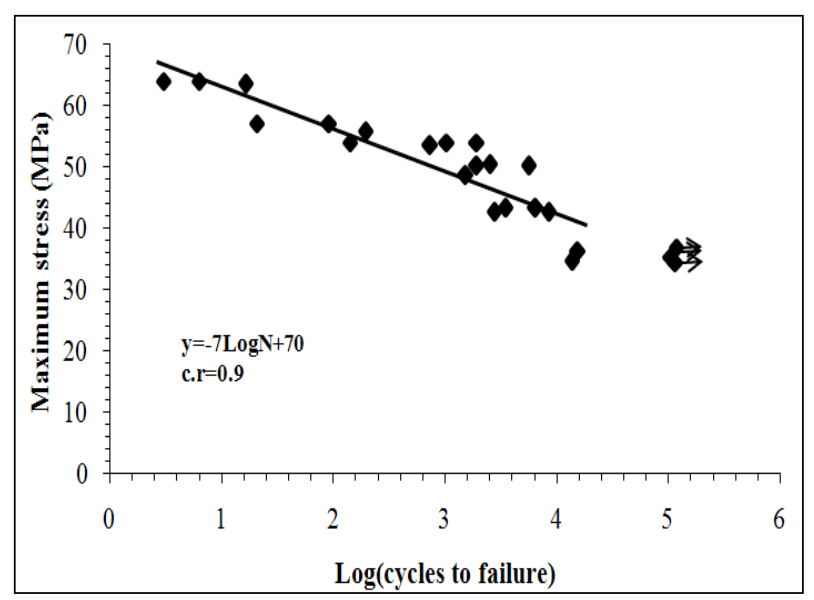

Figure 6. Curve of Wöhler (molding flow direction)

As it appears on the curve the results of materials lifetimes between specimens subjected to the same loading level and tried in the same conditions of repeated solicitation are characterized by a significant scatter. This scatter is the consequence of the heterogeneity of the studied laminated composite materials. Indeed, the characteristics of specimens such as the dimensions, the position, the shape, the orientation, the distribution, the density and the shape of the defects, the rate of the reinforcements, which are conditioned by the manufacturing process as well as the static mechanical resistance are not comparable and differ from a test tube to the other one and from a pick-up position to another one in the plates. The random character of the presence of the defects in the material and of their size is also a consequence of defects initiating's which lead to a higher order dispersion of lifetimes in fatigue.

Furthermore it seems clearly that besides the natural scatter of the material, the behavior in fatigue also possesses an appropriate dispersion usually admitted as a physical fact of the cyclic phenomenon. It is widely reported in technical literature that there is large scatter in results from fatigue tests carried out to characterize the fatigue mechanical properties and the fatigue lifetime of laminated composite materials (Belaadi et al 2013, Redjel and Djeghader 2015. Between the factors affecting the dispersion of the mechanical properties the most significant ones are the heterogeneity, the complex mechanisms of damage during the growing process, the state of samples, the different environmental and manufacturing parameters affecting the production of laminates as it has been observed and confirmed in the case of the laminates experimented in this study. Because of this dispersion a statistical analysis of the mechanical properties is necessary.

The results of the fatigue tests are described according to the linear equation of Wöhler $\sigma_{f a t}=A-B \log \mathrm{N}_{\mathrm{R}}$ where $\sigma_{\text {fat }}$ and $\mathrm{N}_{\mathrm{R}}$ represent the applied maximal stress and the fracture number of cycles respectively. According to Mandell et al. (1982 and 1983), A and B are constants of the tested material. A represents the static fracture strength of the sample. The calculation software performed by linear regression allowed identifying the values of both coefficients A and B of the curve of endurance. The linear regression performed on the experimental points of the figure 8 is given by the following equation of Wôhler:

$$
\sigma_{\text {fat }}=70-7 \log \mathrm{N}_{\mathrm{R}}
$$

The comparison between the value of the coefficient $\mathrm{A}$ and that of $\sigma_{s t}$ shows a $30 \%$ gap in favour of the first one. This gap which remains significant can be partially explained by the large gap between the speeds of loading as well as by the large dispersion of the results of the fatigue test and the consequences of the material inhomogeneities. The value of the coefficient of linear correlation of the curve of Wöhler is slightly low translating the significant dispersion of material lifetimes. This one is largely bound to the heterogeneous nature of the studied composite as well as to the nature of the specimens which rarely have comparable characteristics. The normalized Wöhler's curve is given by the following equation:

$$
\frac{\sigma_{f a t}}{A}=1-\frac{B}{A} \cdot \log \mathrm{N}_{\mathrm{R}}
$$

This shape of this representation illustrated in Fig. 7 allows to reveal a rate of degradation quantified by the absolute value of the slope $(B / A)$ of the equation of Wöhler and which is so constant by decade of cycles. The slope of the normalized straight line is $10 \%$.

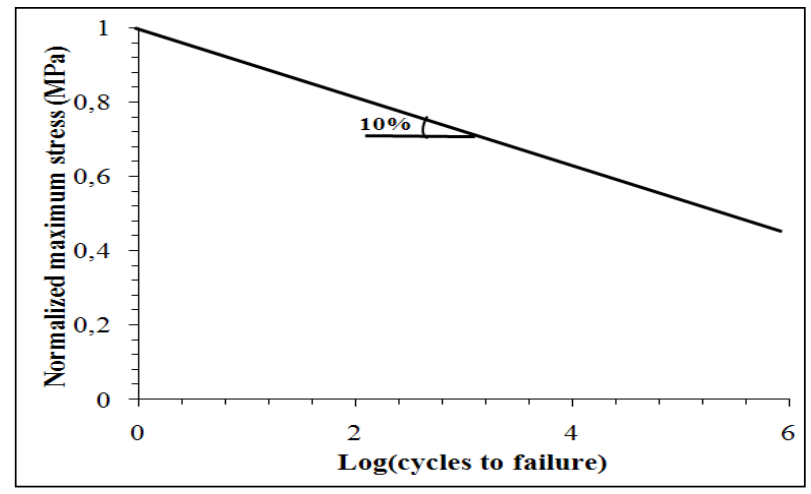

Figure 7. Normalized curve of Wöhler 
This constant degradation rate by decade of cycles is in accordance with those reported on composite materials in the literature and which are generally esteemed in numerous works at $10 \%$ (Redjel 1997).

Various models of representation of the results of fatigue tests were reported in the scientific literature. In this work, the models for which the coefficients are easy to identify from the measurements of the realized tests were selected to confront them with the simplicity of the curve of Wöhler. So and to account for an asymptotic branch for the large numbers of cycles, Basquin (1980) proposes:

$$
\sigma_{\max }=\sigma_{\text {fat }}\left(2 \mathrm{~N}_{\mathrm{R}}\right)^{x}
$$

$\sigma_{\max }$ and $\mathrm{N}_{\mathrm{R}}$ represent the maximal stress of the considered cycle and the fracture number of cycle respectively.

$\sigma_{f a t}$ and $\mathrm{x}$ are constants of the material and represent the coefficient of stress in fatigue and the exponent of Basquin respectively.

Hwang and Han (1986) propose:

$$
\mathrm{N}_{\mathrm{R}}=[C(1-r)]_{c}^{\frac{1}{c}}
$$

$C$ and $c$ are constants of the material and $\mathrm{r}$ represents the applied stress level equal to $\sigma_{\max } / \sigma_{\text {st }}$.

The representation of $\log \left(\sigma_{\max }\right)$ according to $\log \left(2 N_{R}\right)$ for the equation of Basquin and of $\log (1-r)$ according to $\log \left(N_{\mathrm{R}}\right)$ for that of $W$. Hwang and Han are straight lines for which the coefficients allow to identify the constants of every equation. Fig. 8 shows the representation of these two models with that of the equation of Wöhler around the experimental points.

The general trend of the experimental results on a wide range of cycles number in the field of the limited endurance shows a convergence of the models of Hwang and Han, Wöhler and Basquin around the experimental points. In the field of plastic fatigue, the experimental points are better described by the equation of Wöhler. The model of Hwang and Han best describes the experiment in the field of limited endurances. The convergence of the results appears good and acceptable. In the field of the endurances superior to $10^{5}$ cycles, the Basquin equation seems to present a very slow hyperbolic curvature approaching asymptote is a satisfactory approach allowing determining a likely « candidate $»$ limit of endurance.

The straight line of Wöhler also remains an interesting approach for its simplicity. It offers of the middle part an often acceptable representation in view of the significant dispersive aspect of the material lifetime results.

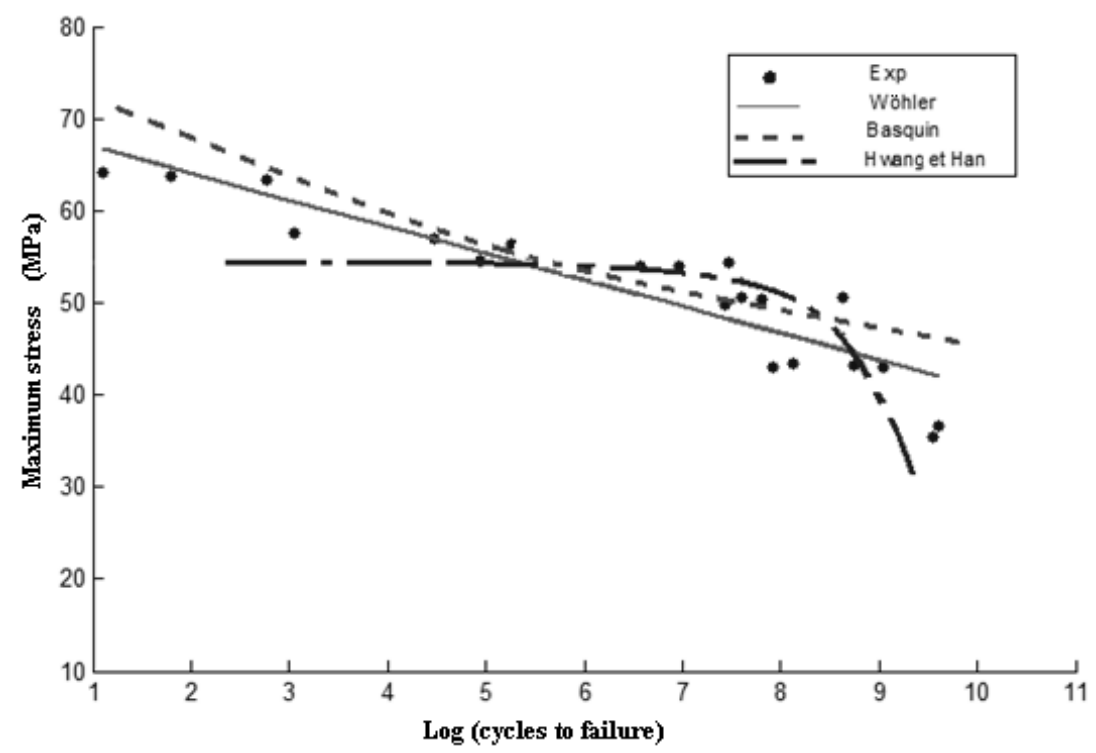

Figure 8. Différent représentations of $\sigma_{\max }$ versus $\log \left(\mathrm{N}_{\mathrm{R}}\right)$ 
Various studies reported that the stages of evolution of the damage in the case of cyclic loading are the same nature than those encountered in static loading but of different chronology and scale. In cyclic request of fatigue, the deterioration of composites takes place from the first cycles of load and increases gradually on surface and inside the volume until the final fracture as shown in Fig. 9 and in Fig. 10.

The state of the damage in fatigue is especially characterized by a combination of density and orientation of micro-cracks. This damage is mainly due to a conjugation of mechanisms complexity of matrix micro-cracking, exfoliation inter facial, deboning, delamination.
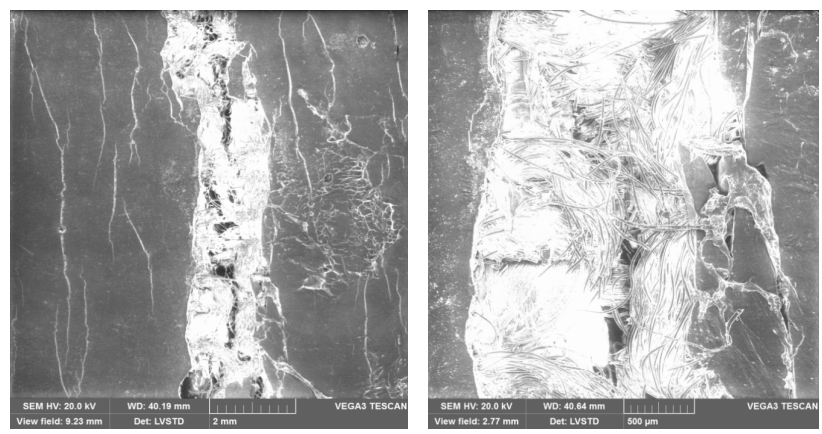

Figure 9. Scanning electronic microscope observations of damage (case of $90 \%$ loading)
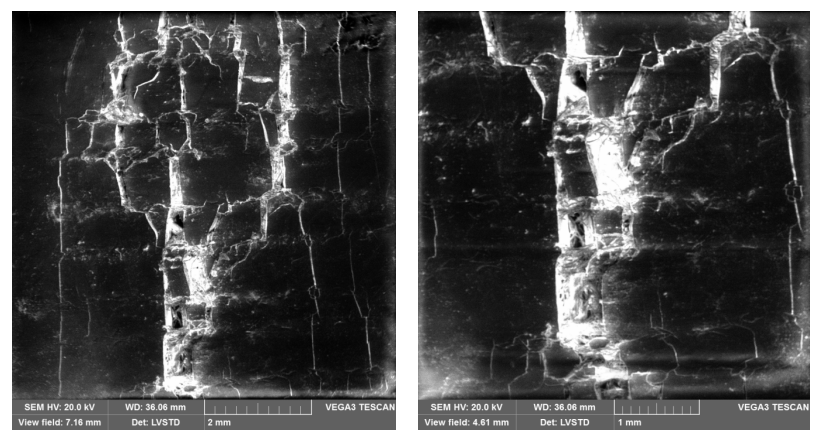

Figure 10. Scanning electronic microscope observations of damage (case of $75 \%$ and $70 \%$ loading)

The evolution of damage so results from the combination and from the multiplication of these numerous mechanisms. The fracture is while the consequence of the evolution of these numerous microstructural mechanisms which interact and which can have three likely possible scenarios.

A first stage of germination of the micro cracks which priming from the pre-existent defects. These microcracks then to develop from the first cycles for coalescing gradually by multiplication and densification during the process of fatigue. Outside, the naked eye cannot either identify them, or see them, but the material gradually undergoes locally modifications. The zones of damage that develop from propagated micro cracks weaken locally the structure of the material.
The second stage reports that the spread of the micro-cracking, the delamination, the densification and the development of the damage taking place. At least one crack will reach a critical size after a certain number of cycles and begins to propagate.

The third stage shows that the resistant section of the specimen is reduced by the crack. The strains and the speeds of strains are important. So the magnitude of the fatigue stress is sufficient to cause sudden failure and the ruin of the specimen.

\section{Conclusions}

This investigation on the fatigue of composite laminate for orthopaedic use has led to the following points:

- The fatigue lifetime results of these composite materials show a significant scatter.

- The damage in fatigue in these materials is characterized by complex mechanisms such as matrix micro cracking, fiber/matrix exfoliation, and delamination. This behaviour makes the life prediction in fatigue difficult.

- The general trend of the experimental results on a wide range of number of cycles in the field of the limited endurance shows a convergence of the models of Hwang and Han, Wöhler and Basquin around the experimental points.

- The straight line of Wöhler's curve remains an interesting approach for its simplicity and offers the middle part an acceptable representation in view of the significant dispersive aspect of the material lifetime results.

\section{Acknowledgements}

The authors thank the national office for manufacture of the prostheses for handicapped ONAAPH Annaba (Algeria), the regional direction of Constantine (Algeria) and the general direction of Algiers (Algeria) for the facilities to supply components having been used for manufacture of the composite plates of this study.

\section{REFERENCES}

[1] Gamelin F.X., Baquet G., Berthoin S., Thevenet D., Nourry C., Nottin S., Bosquet L., (2009) Effect of high intensity intermittent training on heart rate variability in prepubescent children. Eur J Appl Physiol 105:731-738. doi:10.1007/s00421-008-0955-8.

[2] Achouri S., Redjel B., Etude expérimentale et analyse probabiliste du comportement à la rupture en traction de matériaux composites verre-perlon-acrylique à usage orthopédique, Revue des sciences et de la technologie, 
éditée par l'Université Badji Mokhtar d'Annaba, Algérie, $\mathrm{N}^{\circ}$ 29, Octobre 2014, pp., 59-76.

[3] Achouri S., Redjel B., Bouhouche S., The use of the probabilistic two parameters Weibull's model to characterize the failure behavior of glass-perlon reinforced acrylic composite materials, Congrés Algerien de Mécanique CAM2013, Mascara 25-28 Novembre 2013, Algérie.

[4] Bathias C., Baillon J.P., La fatigue des matériaux et des structures, Collection UTC Ed. S.A. Maloine Paris - France $1980,547 \mathrm{p}$.

[5] Belaadi A., Bezazi A., Bourchak M., Scarpa F., Tensile static and fatigue behavior of sisal fibres, Materials and Design, 46, 2013, pp76-83.

[6] Belaadi A., Bezazi A., Maache M., Scarpa F., Fatigue in sisal fiber reinforced polyester composites: hysteresis and energy dissipation, Procedia Engineering, 74, 2014, pp. $325-328$

[7] Bezazi A., Etude théorique et expérimentale des matériaux composites stratifiés et sandwichs sollicités en flexion 3 points, Thèse de doctorat d'état, Département Génie Mécanique, Université Badji Mokhtar Annaba, Algérie, Mars 2003

[8] Boukharouba W., Bezazi A., Scarpa F., Identification and prediction of cyclic fatigue behavior on sandwich panels, Measurement, 53, 2014, pp.161-170

[9] Gonzalo M., Dominguez A., Prediction of very high cycle fatigue failure for high strength steels, based on the inclusion geometrical properties, Mechanics of Material 40 (2008) 636-640

[10] Hwang H., Han K.S., Fatigue of composites-Fatigue modulus concept and life prediction, Journal of Composite Materials, 20, March, 1986

[11] Krawczak P., Essais des plastiques renforcés, Techniques de l'Ingénieur, traité plastiques et composites, AM5405, p. 8, 26 pages, Doc. 1-10

[12] Mandell J.F., Huang D.D., Mc Garry F.J., ASTM STP 772, B.A. Sanders Editor, 1982, pp. 3-32

[13] Mandell J.F., Mc Garry F.J., Huang D.D., Li C.G., Some effects of matrix and interface properties on their fatigue of short fiber reinforced thermoplastics, Polymer Composites, Vol. 4, N 1, January 1983, pp. 32-39

[14] Ngarmaïm N., Tikri B., Bassa B., Kimtangar N., Pennec F., Robert J.L., A New Expression of the Curve S-N in Fatigue based on the Concept of the "Weakest Link" of Weibull, Global Journal of Researches in Engineering: A Mechanical and Mechanics Engineering Volume 14 Issue 3 Version 1.0 2014, pp. 21- 26.

[15] Pauchard V., Boulharts-Campion H., Grosjean F., Odru P., Chateauminois A., Développement d'un modèle de durabilité de poutres composites unidirectionnelles renforcées par des fibres de verre, Oil \& Gas, Science and Technology Rev., IFP, Vol. 56 (2001), No. 6, pp. 581-595

[16] Perrot Y., Influence des propriétés de la matrice sur le comportement mécanique de matériaux composites verre/polyester utilisés en construction navale de plaisance Cas des résines polyester limitant les émissions de styrène,
Thèse de doctorat, Université Bretagne Sud (France), 28 novembre 2006.

[17] Redjel B., Fatigue damage in short fiber reinforced composite materials in $8^{\text {th }}$ International Conference on Fatigue of Composites, SF2M, Eighth International Spring Meeting, Ed. S. Degallaix, C. Bathias, R. Fougères, Paris 3-4-5 June 1997, pp. 165-172.

[18] Redjel B., Djeghader D., "Influence du temps d'immersion dans l'eau de mer sur la tenue en fatigue d'un matériau composite multidirectionnel verre-polyester» 22ème Congrès Français de Mécanique, CFM'15, Lyon 24 au 28 Aout 2015, (France).

[19] Soh Fotsing B., Maronne E., Nadjitonon N., Robert J.L., Intégration d'une démarche fiabiliste dans l'exploitation des critères de fatigue multiaxiaux. $23^{\text {ème }}$ Journée de Printemps de la Commission de Fatigue. Du 25 au 26 mai 2004. 